\title{
A hybrid iteration scheme for equilibrium problems and common fixed point problems of generalized quasi- $\varphi$-asymptotically nonexpansive mappings in Banach spaces
}

Jing Zhao ${ }^{*}$ and Songnian He

* Correspondence: zhaojing200103@163.com College of Science, Civil Aviation University of China, Tianjin 300300 P.R. China

\begin{abstract}
In this article, we introduce an iterative algorithm for finding a common element of the set of common fixed points of a finite family of closed generalized quasi- $\boldsymbol{\varphi}$ asymptotically nonexpansive mappings and the set of solutions of equilibrium problem in Banach spaces. Then we study the strong convergence of the algorithm. Our results improve and extend the corresponding results announced by many others.

Mathematics Subject Classification (2000): 47H09; 47H10; 47J05; 54H25.

Keywords: equilibrium problem, generalized quasi- $\varphi$-asymptotically nonexpansive mapping, strong convergence, common fixed point, Banach space
\end{abstract}

\section{Introduction and preliminary}

Let $E$ be a Banach space with the dual $E^{*}$. Let $C$ be a nonempty closed convex subset of $E$ and $f: C \times C \rightarrow \mathbb{R}$ a bifunction, where $\mathbb{R}$ is the set of real numbers. The equilibrium problem for $f$ is to find $\hat{x} \in C$ such that

$$
f(\widehat{x}, y) \geq 0
$$

for all $y \in C$. The set of solutions of (1.1) is denoted by $E P(f)$. Given a mapping $T: C$ $\rightarrow E^{*}$, let $f(x, y)=\langle T x, y-x\rangle$ for all $x, y \in C$. Then $\hat{x} \in E P(f)$ if and only if $\langle T \hat{x}, y-\hat{x}\rangle \geq 0$ for all $y \in C$, i.e., $\hat{x}$ is a solution of the variational inequality. Numerous problems in physics, optimization, engineering and economics reduce to find a solution of (1.1). Some methods have been proposed to solve the equilibrium problem; see, for example, Blum-Oettli [1] and Moudafi [2]. For solving the equilibrium problem, let us assume that $f$ satisfies the following conditions:

(A1) $f(x, x)=0$ for all $x \in C$;

(A2) $f$ is monotone, that is, $f(x, y)+f(y, x) \leq 0$ for all $x, y \in C$;

(A3) for each $x, y, z \in C, \lim _{t \rightarrow 0} f(t z+(1-t) x, y) \leq f(x, y)$;

(A4) for each $x \in C$, the function $y \mapsto f(x, y)$ is convex and lower semicontinuous.

Let $E$ be a Banach space with the dual $E^{*}$. We denote by $J$ the normalized duality mapping from $E$ to $2^{E^{*}}$ defined by

(C) 2012 Zhao and He; licensee Springer. This is an Open Access article distributed under the terms of the Creative Commons Attribution License (http://creativecommons.org/licenses/by/2.0), which permits unrestricted use, distribution, and reproduction in any medium, provided the original work is properly cited. 


$$
J(x)=\left\{x^{*} \in E^{*}:\left\langle x, x^{*}\right\rangle=\|x\|^{2}=\left\|x^{*}\right\|^{2}\right\},
$$

where $\langle\cdot, \cdot\rangle$ denotes the generalized duality pairing. We know that if $E$ is uniformly smooth, strictly convex, and reflexive, then the normalized duality mapping $J$ is singlevalued, one-to-one, onto and uniformly norm-to-norm continuous on each bounded subset of $E$. Moreover, if $E$ is a reflexive and strictly convex Banach space with a strictly convex dual, then $J^{1}$ is single-valued, one-to-one, surjective, and it is the duality mapping from $E^{* *}$ into $E$ and thus $J J^{-1}=I_{E^{*}}$ and $J^{-1} J=I_{E}$ (see, [3]). It is also well known that if $E$ is uniformly smooth if and only if $E^{*}$ is uniformly convex.

Let $C$ be a nonempty closed convex subset of a Banach space $E$ and $T: C \rightarrow C$ a mapping. A point $x \in C$ is said to be a fixed point of $T$ provided $T x=x$. In this article, we use $F(T)$ to denote the fixed point set and use $\rightarrow$ to denote the strong convergence. Recall that a mapping $T: C \rightarrow C$ is called nonexpansive if

$$
\|T x-T y\| \leq\|x-y\|, \forall x, y \in C .
$$

A mapping $T: C \rightarrow C$ is called asymptotically nonexpansive if there exists a sequence $\left\{k_{n}\right\}$ of real numbers with $k_{n} \rightarrow 1$ as $n \rightarrow \infty$ such that

$$
\left\|T^{n} x-T^{n} y\right\| \leq k_{n}\|x-y\|, \quad \forall x, y \in C, \quad \forall n \geq 1 .
$$

The class of asymptotically nonexpansive mappings was introduced by Goebel and Kirk [4] in 1972. They proved that, if $C$ is a nonempty bounded closed convex subset of a uniformly convex Banach space $E$, then every asymptotically nonexpansive selfmapping $T$ of $C$ has a fixed point. Further, the set $F(T)$ is closed and convex. Since 1972, a host of authors have studied the weak and strong convergence problems of the iterative algorithms for such a class of mappings (see, e.g., [4-6] and the references therein).

It is well known that if $C$ is a nonempty closed convex subset of a Hilbert space $H$ and $P_{C}: H \rightarrow C$ is the metric projection of $H$ onto $C$, then $P_{C}$ is nonexpansive. This fact actually characterizes Hilbert spaces and consequently, it is not available in more general Banach spaces. In this connection, Alber [7] recently introduced a generalized projection operator $\Pi_{C}$ in a Banach space $E$ which is an analogue of the metric projection in Hilbert spaces.

Next, we assume that $E$ is a smooth Banach space. Consider the functional defined by

$$
\phi(x, y)=\|x\|^{2}-2\langle x, J y\rangle+\|y\|^{2}, \quad \forall x, y \in E .
$$

Following Alber [7], the generalized projection $\Pi_{C}: E \rightarrow C$ is a mapping that assigns to an arbitrary point $x \in E$ the minimum point of the functional $\varphi(y, x)$, that is, $\prod_{C} x=\bar{x}$, where $\bar{x}$ is the solution to the following minimization problem:

$$
\phi(\bar{x}, x)=\inf _{y \in C} \phi(y, x) .
$$

It follows from the definition of the function $\varphi$ that

$$
(\|y\|-\|x\|)^{2} \leq \phi(y, x) \leq(\|y\|+\|x\|)^{2}, \quad \forall x, y \in E .
$$


If $E$ is a Hilbert space, then $\varphi(y, x)=\|y-x\|^{2}$ and $\Pi_{C}=P_{C}$ is the metric projection of $H$ onto $C$.

Remark 1.1 [8,9] If $E$ is a reflexive, strictly convex and smooth Banach space, then for $x, y \in E, \varphi(x, y)=0$ if and only if $x=y$.

Let $C$ be a nonempty, closed and convex subset of a smooth Banach $E$ and $T$ a mapping from $C$ into itself. The mapping $T$ is said to be $\varphi$-nonexpansive if $\varphi(T x, T y) \leq \varphi$ $(x, y), \forall x, y \in C$. The mapping $T$ is said to be quasi- $\varphi$-nonexpansive if $F(T) \neq \emptyset, \varphi(p$, $T x) \leq \varphi(p, x), \forall x \in C, p \in F(T)$. The mapping $T$ is said to be $\varphi$-asymptotically nonexpansive if there exists some real sequence $\left\{k_{n}\right\}$ with $k_{n} \geq 1$ and $k_{n} \rightarrow 1$ as $n \rightarrow \infty$ such that $\varphi\left(T^{n} x, T^{n} y\right) \leq k_{n} \varphi(x, y), \forall x, y \in C$. The mapping $T$ is said to be quasi- $\varphi$-asymptotically nonexpansive if $F(T) \neq \varnothing$ and there exists some real sequence $\left\{k_{n}\right\}$ with $k_{n} \geq 1$ and $k_{n} \rightarrow 1$ as $n \rightarrow \infty$ such that $\varphi\left(p, T^{n} x\right) \leq k_{n} \varphi(p, x), \forall x \in C, p \in F(T)$. The mapping $T$ is said to be generalized quasi- $\varphi$-asymptotically nonexpansive if $F(T) \neq \varnothing$ and there exist nonnegative real sequences $\left\{k_{n}\right\}$ and $\left\{c_{n}\right\}$ with $k_{n} \geq 1, \lim _{n \rightarrow \infty} k_{n}=1$ and $\lim _{n \rightarrow \infty}$ $c_{n}=0$ such that $\varphi\left(p, T^{n} x\right) \leq k_{n} \varphi(p, x)+c_{n}, \forall x \in C, p \in F(T)$. The mapping $T$ is said to be asymptotically regular on $C$ if, for any bounded subset $K$ of $C, \lim \sup _{n \rightarrow \infty}\left\{\| T^{n}\right.$ $\left.{ }^{+1} x-T^{n} x \|: x \in K\right\}=0$. The mapping $T$ is said to be closed on $C$ if, for any sequence $\left\{x_{n}\right\}$ such that $\lim _{n \rightarrow \infty} x_{n}=x_{0}$ and $\lim _{n \rightarrow \infty} T x_{n}=y_{0}$, then $T x_{0}=y_{0}$.

We remark that a $\varphi$-asymptotically nonexpansive mapping with a nonempty fixed point set $F(T)$ is a quasi- $\varphi$-asymptotically nonexpansive mapping, but the converse may be not true. The class of generalized quasi- $\varphi$-asymptotically nonexpansive mappings is more general than the class of quasi- $\varphi$-asymptotically nonexpansive mappings and $\varphi$-asymptotically nonexpansive mappings. The following example shows that the inclusion is proper. Let $K=\left[-\frac{1}{\pi}, \frac{1}{\pi}\right]$ and define (see [10]) $T x=\frac{x}{2} \sin \left(\frac{1}{x}\right)$ if $x \neq 0$ and $T x$ $=0$ if $x=0$. Then $T^{n} x \rightarrow 0$ uniformly but $T$ is not Lipschitzian. It should be noted that $F(T)=\{0\}$. For each fixed $n$, define $f_{n}(x)=\left\|T^{n} x\right\|^{2}-\|x\|^{2}$ for $x \in K$. Set $c_{n}=$ sup$x \in K\left\{f_{n}(x), 0\right\}$. Then $\lim _{n \rightarrow \infty} c_{n}=0$ and

$$
\phi\left(0, T^{n} x\right)=\left\|T^{n} x\right\|^{2} \leq\|x\|^{2}+c_{n}=\phi(0, x)+c_{n} .
$$

This show that $T$ is a generalized quasi- $\varphi$-asymptotically nonexpansive but it is not quasi- $\varphi$-asymptotically nonexpansive and $\varphi$-asymptotically nonexpansive. Recently, many authors studied the problem of finding a common element of the set of fixed points of nonexpansive or quasi- $\varphi$-asymptotically nonexpansive mappings and the set of solutions of an equilibrium problem in the frame work of Hilbert spaces and Banach spaces respectively; see, for instance, [11-15] and the references therein.

In 2009, Cho, Qin and Kang [16] introduced the following iterative scheme on a closed quasi- $\varphi$-asymptotically nonexpansive mapping:

$$
\left\{\begin{array}{l}
x_{0} \in E, C_{1}=C, \quad x_{1}=\prod_{C_{1}} x_{0} \\
y_{n}=J^{-1}\left(\alpha_{n} J x_{1}+\left(1-\alpha_{n}\right) J T^{n} x_{n}\right) \\
C_{n+1}=\left\{z \in C_{n}: \phi\left(z, y_{n}\right) \leq \phi\left(z, x_{n}\right)+\alpha_{n} M\right\} \\
x_{n+1}=\prod_{C_{n+1}} x_{1}, \quad \forall n \geq 0 .
\end{array}\right.
$$

Strong convergence theorems of fixed points are established in a uniformly smooth and uniformly convex Banach space. 
Recently, Takahashi and Zembayashi [17] introduced the following iterative process:

$$
\left\{\begin{array}{l}
x_{0}=x \in C \\
y_{n}=J^{-1}\left(\alpha_{n} J x_{n}+\left(1-\alpha_{n}\right) J S x_{n}\right), \\
u_{n} \in C \text { such that } f\left(u_{n}, \gamma\right)+\frac{1}{r_{n}}\left\langle y-u_{n}, J u_{n}-J y_{n}\right\rangle \geq 0, \quad \forall y \in C, \\
H_{n}=\left\{z \in C: \phi\left(z, u_{n}\right) \leq \phi\left(z, x_{n}\right)\right\} \\
W_{n}=\left\{z \in C:\left\langle x_{n}-z, J x-J x_{n}\right\rangle \geq 0\right\}, \\
x_{n+1}=\prod_{H_{n} \cap W_{n}} x, \quad \forall_{n} \geq 1,
\end{array}\right.
$$

where $f: C \times C \rightarrow \mathbb{R}$ is a bifunction satisfying (A1)-(A4), $J$ is the normalized duality mapping on $E$ and $S: C \rightarrow C$ is a relatively nonexpansive mapping. They proved the sequences $\left\{x_{n}\right\}$ defined by (1.2) converge strongly to a common point of the set of solutions of the equilibrium problem (1.1) and the set of fixed points of $S$ provided the control sequences $\left\{\alpha_{n}\right\}$ and $\left\{r_{n}\right\}$ satisfy appropriate conditions in Banach spaces.

In this article, inspired and motivated by the works mentioned above, we introduce an iterative process for finding a common element of the set of common fixed points of a finite family of closed generalized quasi- $\varphi$-asymptotically nonexpansive mappings and the solution set of equilibrium problem in Banach spaces. In the meantime, the method of the proof is different from the original one. The results presented in this article improve and generalize the corresponding results announced by many others.

Let $C_{n}$ be a sequence of nonempty closed convex subsets of a reflexive Banach space $E$. We denote two subsets $s-L i_{n} C_{n}$ and $w-L s_{n} C_{n}$ as follows: $x \in s-L i_{n} C_{n}$ if and only if there exists $\left\{x_{n}\right\} \subset E$ such that $\left\{x_{n}\right\}$ converges strongly to $x$ and that $x_{n} \in C_{n}$ for all $n$ $\geq 0$. Similarly, $y \in w-L s_{n} C_{n}$ if and only if there exists a subsequence $\left\{C_{n_{i}}\right\}$ of $\left\{C_{n}\right\}$ and a sequence $\left\{y_{i}\right\} \subset E$ such that $\left\{y_{i}\right\}$ converges weakly to $y$ and that $y_{i} \in C_{n_{i}}$ for all $i \geq 0$. We define the Mosco convergence [18] of $\left\{C_{n}\right\}$ as follows: If $C_{0}$ satisfies that $C_{0}=s$ $L i_{n} C_{n}=w-L s_{n} C_{n}$, it is said that $\left\{C_{n}\right\}$ converges to $C_{0}$ in the sense of Mosco and we write $C_{0}=M-\lim _{n \rightarrow \infty} C_{n}$. For more detail, see [19].

In order to obtain the main results of this paper, we need the following lemmas.

Lemma 1.2 [20]Let E be a smooth and uniformly convex Banach space and let $\left\{x_{n}\right\}$ and $\left\{y_{n}\right\}$ be sequences in $E$ such that either $\left\{x_{n}\right\}$ or $\left\{y_{n}\right\}$ is bounded. If $\lim _{n \rightarrow \infty} \varphi\left(x_{n}, \mathrm{y}_{\mathrm{n}}\right)=$ 0 , then $\lim _{n \rightarrow \infty}\left\|x_{n}-y_{n}\right\|=0$.

Lemma 1.3 [21] Let E be a smooth, strictly convex and reflexive Banach space having the Kadec-Klee property. Let $\left\{K_{n}\right\}$ be a sequence of nonempty closed convex subsets of $E$. If $K_{0}=M-\lim _{n \rightarrow \infty} K_{n}$ exists and is nonempty, then $\left\{\prod_{K_{n}} x\right\}_{\text {converges strongly to }}$ $\left\{\prod_{K_{0}} x\right\}$ for each $x \in C$.

Lemma 1.4 $[8,22]$ Let $E$ be a uniformly convex Banach space, $s>0$ a positive number and $B_{s}(0)$ a closed ball of $E$. Then there exists a strictly increasing, continuous, and convex function $g:[0, \infty) \rightarrow[0, \infty)$ with $g(0)=0$ such that

$$
\left\|\sum_{i=0}^{N}\left(\alpha_{i} x_{i}\right)\right\|^{2} \leq \sum_{i=0}^{N} \alpha_{i}\left\|x_{i}\right\|^{2}-\alpha_{k} \alpha_{l} g\left(\left\|x_{k}-x_{l}\right\|\right)
$$

for any $k, l \in\{0,1, \ldots, N\}$, for all $x_{0}, x_{1}, \ldots, x_{N} \in B_{s}(0)=\{x \in E:\|x\| \leq s\}$ and $\alpha_{0}$, $\alpha_{1}, \ldots, \alpha_{n} \in[0,1]$ such that $\sum_{i=0}^{N} \alpha_{i}=1$.

Lemma 1.5 [1] Let $C$ be a closed convex subset of a smooth, strictly convex, and reflexive Banach space $E$, let $f$ be a bifunction from $C \times C$ to $\mathbb{R}$ satisfying (A1)-(A4), and letr $>0$ and $x \in E$. Then, there exists $z \in C$ such that 


$$
f(z, y)+\frac{1}{r}\langle y-z, J z-J x\rangle \geq 0, \quad \forall y \in C .
$$

Lemma 1.6 [17]Let $C$ be a closed convex subset of a uniformly smooth, strictly convex, and reflexive Banach space $E$. Let $f$ be a bifunction from $C \times C$ to $\mathbb{R}$ satisfying (A1)-(A4). For $r>0$ and $x \in E$, define a mapping $T_{r}: E \rightarrow C$ as follows:

$$
T_{r}(x)=\left\{z \in C: f(z, y)+\langle B x, y-z\rangle+\frac{1}{r}\langle y-z, J z-J x\rangle \geq 0, \quad \forall y \in C\right\}
$$

for all $x \in E$. Then, the following hold:

(1) $T_{r}$ is single-valued;

(2) $T_{r}$ is firmly nonexpansive, i.e., for any $x, y \in E$,

$$
\left\langle T_{r} x-T_{r} y_{,} J T_{r} x-J T_{r} y\right\rangle \leq\left\langle T_{r} x-T_{r} y_{,} J x-J y\right\rangle ;
$$

(3) $F\left(T_{r}\right)=E P(f)$;

(4) $E P(f)$ is closed and convex;

(5) $\varphi\left(q, T_{r} x\right)+\varphi\left(T_{r} x, x\right) \leq \varphi(q, x), \forall q \in F\left(T_{r}\right)$.

Lemma 1.7 Let $E$ be a uniformly convex and uniformly smooth Banach space, $C$ a nonempty, closed and convex subset of $E$ and $T$ a closed generalized quasi- $\varphi$-asymptotically nonexpansive mapping from $C$ into itself. Then $F(T)$ is a closed convex subset of $C$. Proof. We first show that $F(T)$ is closed. To see this, let $\left\{p_{n}\right\}$ be a sequence in $F(T)$ with $p_{n} \rightarrow p$ as $n \rightarrow \infty$, we shall prove that $p \in F(T)$. By using the definition of $T$, we have

$$
\phi\left(p_{n}, T^{n} p\right) \leq k_{n} \phi\left(p_{n}, p\right)+c_{n}
$$

which implies that $\varphi\left(p_{n}, T^{n} p\right) \rightarrow 0$ as $n \rightarrow \infty$. It follows from Lemma 1.2 that $p_{n}$ $-T^{n} p \rightarrow 0$ as $n \rightarrow \infty$ and hence $T^{n} p \rightarrow p$ as $n \rightarrow \infty$. We have $T\left(T^{n} p\right)=T^{n+1} p \rightarrow \mathrm{p}$ as $n \rightarrow \infty$. It follows from the closedness of $T$ that $T p=p$. We next show that $F(T)$ is convex. To prove this, for arbitrary $p, q \in F(T), t \in(0,1)$, we set $w=t p+(1-t) q$. By (1.3), we have

$$
\begin{aligned}
& \phi\left(w, T^{n} w\right) \\
= & \|w\|^{2}-2\left\langle w, J T^{n} w\right\rangle+\left\|T^{n} w\right\|^{2} \\
= & \|w\|^{2}-2 t\left\langle p, J T^{n} w\right\rangle-2(1-t)\left\langle q, J T^{n} w\right\rangle+\left\|T^{n} w\right\|^{2} \\
= & \|w\|^{2}+t \phi\left(p, T^{n} w\right)+(1-t) \phi\left(q, T^{n} w\right)-t\|p\|^{2}-(1-t)\|q\|^{2} \\
\leq & \|w\|^{2}+t k_{n} \phi(p, w)+t c_{n}+(1-t) k_{n} \phi(q, w)+(1-t) c_{n}-t\|p\|^{2}-(1-t)\|q\|^{2} \\
= & \|w\|^{2}+t k_{n}\|p\|^{2}-2 t k_{n}\langle p, J w\rangle+t k_{n}\|w\|^{2}+(1-t) k_{n}\|q\|^{2} \\
& -2(1-t) k_{n}\langle q, J w\rangle+(1-t) k_{n}\|w\|^{2}+c_{n}-t\|p\|^{2}-(1-t)\|q\|^{2} \\
= & \left(k_{n}-1\right)\left(t\|p\|^{2}+(1-t)\|q\|^{2}\right)+\|w\|^{2}+k_{n}\|w\|^{2}-2 k_{n}(w, J w)+c_{n} \\
= & \left(k_{n}-1\right)\left(t\|p\|^{2}+(1-t)\|q\|^{2}\right)+\left(k_{n}+1\right)\|w\|^{2}-2 k_{n}\|w\|^{2}+c_{n} \\
= & \left(k_{n}-1\right)\left(t\|p\|^{2}+(1-t)\|q\|^{2}-\|w\|^{2}\right)+c_{n}
\end{aligned}
$$

which implies that $\varphi\left(w, T^{n} w\right) \rightarrow 0$ as $n \rightarrow \infty$. By Lemma 1.2, we obtain $T^{n} w \rightarrow w$ as $n \rightarrow \infty$, and hence $T\left(T^{n} w\right)=T^{n+1} w \rightarrow w$ as $n \rightarrow \infty$. Since $T$ is closed, we see that $w=$ $T w$. This completes the proof. 


\section{Main results}

Theorem 2.1 Let $C$ be a nonempty, closed and convex subset of a uniformly convex and uniformly smooth real Banach space $E$ and let $T_{i}: C \rightarrow C$ be a closed and generalized quasi- $\varphi$-asymptotically nonexpansive mapping with real sequences $\left\{k_{n, i}\right\} \subset[1, \infty)$ and $\left\{c_{n, i}\right\} \subset[0, \infty)$ such that $\lim _{n \rightarrow \infty} k_{n, i}=1$ and $\lim _{n \rightarrow \infty} c_{n, i}=0$ for each $1 \leq i \leq N$. Let $f$ be a bifunction from $C \times C$ to $\mathbb{R}$ satisfying (A1)-(A4). Assume that $T_{i}$ is asymptotically regular on $C$ for each $1 \leq i \leq N$ and $F=\left(\bigcap_{i=1}^{N} F\left(T_{i}\right)\right) \bigcap E P(f) \neq \emptyset$. Let $k_{n}=\max _{1 \leq i \leq N}$ $\left\{k_{n}, i\right\}$ and $c_{n}=\max _{1 \leq i \leq N}\left\{c_{n, i}\right\}$. Define a sequence $\left\{x_{n}\right\}$ in $C$ in the following manner:

$$
\left\{\begin{array}{l}
x_{0} \in \text { E chosen arbitrarily, } \\
C_{1}=C, \\
x_{1}=\prod_{C_{1}} x_{0}, \\
y_{n}=J^{-1}\left(\alpha_{n, 0} J x_{n}+\sum_{i=1}^{N} \alpha_{n, i} J T_{i}^{n} x_{n}\right), \\
u_{n} \in C \text { such that } f\left(u_{n}, y\right)+\frac{1}{r_{n}}\left\langle y-u_{n}, J u_{n}-J y_{n}\right\rangle \geq 0, \quad \forall y \in C, \\
C_{n+1}=\left\{z \in C_{n}: \phi\left(z, u_{n}\right) \leq k_{n} \phi\left(z, x_{n}\right)+c_{n}\right\}, \\
x_{n+1}=\prod_{C_{n+1}} x_{1}
\end{array}\right.
$$

for every $n \geq 1$, where $\left\{r_{n}\right\}$ is a real sequence in $[a, \infty)$ for some $a>0, J$ is the normalized duality mapping on $E$. Assume that the control sequences $\left\{\alpha_{n, 0}\right\},\left\{\alpha_{n, 1}\right\}, \ldots,\left\{\alpha_{n, N}\right\}$ are real sequences in $(0,1)$ satisfy $\sum_{i=0}^{N} \alpha_{n, i}=1$ and $\lim _{\inf _{n \rightarrow \infty}} \alpha_{n, 0} \alpha_{n, i}>0$ for each $i \in$ $\{1,2, \cdots, N\}$. Then the sequence $\left\{x_{n}\right\}$ converges strongly to $\Pi_{F} x_{1}$, where $\Pi_{F}$ is the generalized projection from $C$ into $F$.

Proof. Firstly, by Lemma 1.7, we know that $F\left(T_{i}\right)$ is a closed convex subset of $C$ for every $1 \leq i \leq N$. Hence, $F=\left(\bigcap_{i=1}^{N} F\left(T_{i}\right)\right) \bigcap E P(f) \neq \varnothing$ is a nonempty closed convex subset of $C$ and $\Pi_{F} x_{1}$ is well defined for $x_{1} \in C$. Now we show that $C_{n}$ is closed and convex for each $n \geq 1$. From the definition of $C_{n}$, it is obvious that $C_{n}$ is closed for each $n$ $\geq 1$. We show that $C_{n}$ is convex for each $n \geq 1$. It is obvious that $C_{1}=C$ is convex. Suppose that $C_{n}$ is convex for some integer $n$. Observe that the set

$$
C_{n+1}=\left\{z \in C_{n}: \phi\left(z, u_{n}\right) \leq k_{n} \phi\left(z, x_{n}\right)+c_{n}\right\}
$$

can be written to

$$
C_{n+1}=\left\{z \in C_{n}:\left(1-k_{n}\right)\|z\|^{2}+\left\|u_{n}\right\|^{2}-k_{n}\left\|x_{n}\right\|^{2}-c_{n} \leq 2\left\langle z, J u_{n}-k_{n} J x_{n}\right\rangle\right\} .
$$

For $z_{1}, z_{2} \in C_{n+1} \subset C_{n}$ and $t \in(0,1)$, denote $z=t z_{1}+(1-t) z_{2}$, we have $z \in C_{n}$. Setting $A=\left\|u_{n}\right\|^{2}-k_{n}\left\|x_{n}\right\|^{2}-c_{n}$ and $B=J u_{n}-k_{n} J x_{n}$, by noting that $\|\cdot\|^{2}$ is convex, we have

$$
\|z\|^{2} \leq t\left\|z_{1}\right\|^{2}+(1-t)\left\|z_{2}\right\|^{2} .
$$

So we obtain

$$
\begin{aligned}
\left(1-k_{n}\right)\|z\|^{2}+A & \leq\left(1-k_{n}\right) t\left\|z_{1}\right\|^{2}+\left(1-k_{n}\right)(1-t)\left\|z_{2}\right\|^{2}+A \\
& \leq 2 t\left\langle z_{1}, B\right\rangle+2(1-t)\left\langle z_{2}, B\right\rangle \\
& =2\langle z, B\rangle
\end{aligned}
$$

which implies that $z \in C_{n+1}$, so we get $C_{n+1}$ is convex. Thus, $C_{n}$ is closed and convex for each $n \geq 1$.

Secondly, we prove that $F \subset C_{n}$ for all $n \geq 1$. We do this by induction. For $n=1$, we have $F \subset C=C_{1}$. Suppose that $F \subset C_{n}$ for some $n \geq 1$. Let $p \in F \subset C$. Putting $u_{n}=T_{r_{n}} y_{n}$ for all $n \geq 1$, we have that $T_{r_{n}}$ is quasi- $\varphi$-nonexpansive from Lemma 1.6. 
Since $T_{i}$ is generalized quasi- $\varphi$-asymptotically nonexpansive, by noting that $\|\cdot\|^{2}$ is convex, we have

$$
\begin{aligned}
& \phi\left(p, u_{n}\right) \\
= & \phi\left(p, T_{r_{n}} y_{n}\right) \\
\leq & \phi\left(p, y_{n}\right) \\
= & \phi\left(p, J^{-1}\left(\alpha_{n, 0} J x_{n}+\sum_{i=1}^{N} \alpha_{n, i} J T_{i}^{n} x_{n}\right)\right) \\
= & \|p\|^{2}-2\left\langle p, \alpha_{n, 0} J x_{n}+\sum_{i=1}^{N} \alpha_{n, i} J T_{i}^{n} x_{n}\right\rangle+\left\|\alpha_{n, 0} J x_{n}+\sum_{i=1}^{N} \alpha_{n, i} J T_{i}^{n} x_{n}\right\|^{2} \\
\leq & \|p\|^{2}-2 \alpha_{n, 0}\left\langle p, J x_{n}\right\rangle-2 \sum_{i=1}^{N} \alpha_{n, i}\left\langle p, J T_{i}^{n} x_{n}\right\rangle+\alpha_{n, 0}\left\|x_{n}\right\|^{2}+\sum_{i=1}^{N} \alpha_{n, i}\left\|T_{i}^{n} x_{n}\right\|^{2} \\
= & \alpha_{n, 0} \phi\left(p, x_{n}\right)+\sum_{i=1}^{N} \alpha_{n, i} \phi\left(p, T_{i}^{n} x_{n}\right) \\
\leq & \alpha_{n, 0} \phi\left(p, x_{n}\right)+\sum_{i=1}^{N} \alpha_{n, i} k_{n, i} \phi\left(p, x_{n}\right)+\sum_{i=1}^{N} \alpha_{n, i} c_{n, i} \\
\leq & k_{n} \phi\left(p, x_{n}\right)+c_{n}
\end{aligned}
$$

which infers that $p \in C_{n+1}$, and hence $F \subset C_{n+1}$. This proves that $F \subset C_{n}$ for all $n \geq$ 1 .

Thirdly, we show that $\lim _{n \rightarrow \infty} x_{n}=x^{*}=\prod \bar{C}^{x_{1}}$, where $\bar{C}=\cap_{n=1}^{\infty} C_{n}$. Indeed, since $\left\{C_{n}\right\}$ is a decreasing sequence of closed convex subsets of $E$ such that $\bar{C}=\cap_{n=1}^{\infty} C_{n}$ is nonempty, it follows that

$$
M-\lim _{n \rightarrow \infty} C_{n}=\bar{C}=\cap_{n=1}^{\infty} C_{n} \neq 0 .
$$

By Lemma 1.3, $\left\{x_{n}\right\}=\left\{\Pi_{C_{n}} x_{1}\right\}$ converges strongly to $\left\{x^{*}\right\}=\left\{\Pi_{\bar{C}^{\prime}} x_{1}\right\}$ and $\left\{x_{n}\right\}$ is bounded.

Fourthly, we prove that $x^{*} \in F$.

Since $x_{n+1}=\Pi_{C_{n+1}} x_{1} \in C_{n+1}$, from the definition of $C_{n+1}$, we get

$$
\phi\left(x_{n+1}, u_{n}\right) \leq k_{n} \phi\left(x_{n+1}, x_{n}\right)+c_{n} .
$$

From $\lim _{n} \rightarrow \infty x_{n}=x^{*}$, one obtain $\varphi\left(x_{n+1}, x_{n}\right) \rightarrow 0$ as $n \rightarrow \infty$, and it follows from $\lim _{n \rightarrow \infty} c_{n}=0$ we have

$$
\phi\left(x_{n+1}, u_{n}\right)=0 .
$$

Thus, $\lim _{n \rightarrow \infty}\left\|x_{n+1}-u_{n}\right\|=0$ by Lemma 1.2. It should be noted that

$$
\left\|x_{n}-u_{n}\right\| \leq\left\|x_{n}-x_{n+1}\right\|+\left\|x_{n+1}-u_{n}\right\|
$$

for all $n \geq 1$. It follows that

$$
\lim _{n \rightarrow \infty}\left\|x_{n}-u_{n}\right\|=0,
$$

which implies that $u_{n} \rightarrow x^{*}$ as $n \rightarrow \infty$. Since $J$ is uniformly norm-to-norm continuous on bounded sets, from (2.3), we have 


$$
\lim _{n \rightarrow \infty}\left\|J x_{n}-J u_{n}\right\|=0 .
$$

Let $s=\sup \left\{\left\|x_{n}\right\|,\left\|T_{1}^{n} x_{n}\right\|,\left\|T_{2}^{n} x_{n}\right\|, \ldots,\left\|T_{N}^{n} x_{n}\right\|: n \in \mathbb{N}\right\}$. Since $E$ is uniformly smooth Banach space, we know that $E^{*}$ is a uniformly convex Banach space. Therefore, from Lemma 1.4 we have, for any $p \in F$, that

$$
\begin{aligned}
& \phi\left(p, u_{n}\right) \\
= & \phi\left(p, T_{r_{n}} y_{n}\right) \\
\leq & \phi\left(p, y_{n}\right) \\
= & \phi\left(p, J^{-1}\left(\alpha_{n, 0} J x_{n}+\sum_{i=1}^{N} \alpha_{n, i} J T_{i}^{n} x_{n}\right)\right) \\
= & \|p\|^{2}-2 \alpha_{n, 0}\left\langle p, J x_{n}\right\rangle-2 \sum_{i=1}^{N} \alpha_{n, i}\left\langle p, J T_{i}^{n} x_{n}\right\rangle+\left\|\alpha_{n, 0} J x_{n}+\sum_{j=1}^{N} \alpha_{n, j} J T_{i}^{n} x_{n}\right\|^{2} \\
\leq & \|p\|^{2}-2 \alpha_{n, 0}\left\langle p, J x_{n}\right\rangle-2 \sum_{i=1}^{N} \alpha_{n, i}\left\langle p, J T_{i}^{n} x_{n}\right\rangle \\
& +\alpha_{n, 0}\left\|x_{n}\right\|^{2}+\sum_{i=1}^{N} \alpha_{n, i}\left\|T_{i}^{n} x_{n}\right\|^{2}-\alpha_{n, 0} \alpha_{n, 1} g\left(\left\|J x_{n}-J T_{1}^{n} x_{n}\right\|\right) \\
= & \alpha_{n, 0} \phi\left(p, x_{n}\right)+\sum_{i=1}^{N} \alpha_{n, i} \phi\left(p, T_{i}^{n} x_{n}\right)-\alpha_{n, 0} \alpha_{n, 1} g\left(\left\|J x_{n}-J T_{1}^{n} x_{n}\right\|\right) \\
\leq & \alpha_{n, 0} \phi\left(p, x_{n}\right)+\sum_{i=1}^{N} \alpha_{n, i} k_{n, i} \phi\left(p, x_{n}\right)+\sum_{i=1}^{N} \alpha_{n, i} c_{n, i}-\alpha_{n, 0} \alpha_{n, 1} g\left(\left\|J x_{n}-J T_{1}^{n} x_{n}\right\|\right) \\
\leq & k_{n} \phi\left(p, x_{n}\right)+c_{n}-\alpha_{n, 0} \alpha_{n, 1} g\left(\left\|J x_{n}-J T_{1}^{n} x_{n}\right\|\right) \\
= & \phi\left(p, x_{n}\right)+\left(k_{n}-1\right) \phi\left(p, x_{n}\right)+c_{n}-\alpha_{n, 0} \alpha_{n, 1} g\left(\left\|J x_{n}-J T_{1}^{n} x_{n}\right\|\right) .
\end{aligned}
$$

Therefore, we have

$$
\alpha_{n, 0} \alpha_{n, 1} g\left(\left\|J x_{n}-J T_{1}^{n} x_{n}\right\|\right) \leq \phi\left(p, x_{n}\right)-\phi\left(p, u_{n}\right)+\left(k_{n}-1\right) \phi\left(p, x_{n}\right)+c_{n} .
$$

On the other hand, we have

$$
\begin{aligned}
& \left|\phi\left(p, x_{n}\right)-\phi\left(p, u_{n}\right)\right| \\
= & \left|\left\|x_{n}\right\|^{2}-\left\|u_{n}\right\|^{2}-2\left\langle p, J x_{n}-J u_{n}\right\rangle\right| \\
\leq & \left|\left\|x_{n}\right\|-\left\|u_{n}\right\|\right|\left(\left\|x_{n}\right\|+\left\|u_{n}\right\|\right)+2\left\|J x_{n}-J u_{n}\right\|\|p\| \\
\leq & \left\|x_{n}-u_{n}\right\|\left(\left\|x_{n}\right\|+\left\|u_{n}\right\|\right)+2\left\|J x_{n}-J u_{n}\right\|\|p\| .
\end{aligned}
$$

It follows from (2.3) and (2.4) that

$$
\lim _{n \rightarrow \infty}\left(\phi\left(p, x_{n}\right)-\phi\left(p, u_{n}\right)\right)=0 .
$$

Since $\lim _{n \rightarrow \infty} k_{n}=1, \lim _{n \rightarrow \infty} c_{n}=0$ and $\lim _{\inf _{n \rightarrow \infty}} \alpha_{n, 0} \alpha_{n, 1}>0$, from (2.5) and (2.6) we have

$$
\lim _{n \rightarrow \infty} g\left(\left\|J x_{n}-J T_{1}^{n} x_{n}\right\|\right)=0 .
$$


Therefore, from the property of $g$, we obtain

$$
\lim _{n \rightarrow \infty}\left\|J x_{n}-J T_{1}^{n} x_{n}\right\|=0 .
$$

Since $J^{1}$ is uniformly norm-to-norm continuous on bounded sets, we have

$$
\lim _{n \rightarrow \infty}\left\|x_{n}-T_{1}^{n} x_{n}\right\|=0,
$$

and hence $\quad T_{1}^{n} x_{n} \rightarrow x^{*} \quad$ as $n \quad \rightarrow \quad \infty$. Since $\left\|T_{1}^{n+1} x_{n}-x^{*}\right\| \leq\left\|T_{1}^{n+1} x_{n}-T_{1}^{n} x_{n}\right\|+\left\|T_{1}^{n} x_{n}-x^{*}\right\|$, it follows from the asymptotical regularity of $T_{1}$ that

$$
\lim _{n \rightarrow \infty}\left\|T_{1}^{n+1} x_{n}-x^{*}\right\|=0 .
$$

That is, $T_{1}\left(T_{1}^{n} x_{n}\right) \rightarrow x^{*}$ as $n \rightarrow \infty$. From the closedness of $T_{1}$, we get $T_{1} x^{*}=x^{*}$. Similarly, one can obtain that $T_{i} x^{*}=x^{*}$ for $i=2, \ldots, N$. So, $x^{*} \in \cap_{i=1}^{N} F\left(T_{i}\right)$.

Now we show $x^{*} \in E P(f)=F\left(T_{r}\right)$. Let $p \in F$. From $u_{n}=T_{r_{n}} y_{n},(2.2)$ and Lemma 1.6, we obtain that

$$
\begin{aligned}
\phi\left(u_{n}, y_{n}\right) & =\phi\left(T_{r_{n}} y_{n}, y_{n}\right) \\
& \leq \phi\left(p, y_{n}\right)-\phi\left(p, T_{r_{n}} y_{n}\right) \\
& \leq \phi\left(p, x_{n}\right)+\left(k_{n}-1\right) \phi\left(p, x_{n}\right)+c_{n}-\phi\left(p, u_{n}\right) .
\end{aligned}
$$

It follows from (2.6), $k_{n} \rightarrow 1$ and $c_{n} \rightarrow 0$ that $\varphi\left(u_{n}, y_{n}\right) \rightarrow 0$ as $n \rightarrow \infty$. Now, by Lemma 1.2, we have that $\left\|u_{n}-y_{n}\right\| \rightarrow 0$ as $n \rightarrow \infty$, and hence, $\left\|J u_{n}-J y_{n}\right\| \rightarrow 0$ as $n \rightarrow$ $\infty$. Since $u_{n} \rightarrow x^{*}$ as $n \rightarrow \infty$, we obtain that $y_{n} \rightarrow x^{*}$. From the assumption $r_{n}>a$, we get

$$
\lim _{n \rightarrow \infty} \frac{\left\|J u_{n}-J y_{n}\right\|}{r_{n}}=0
$$

Noting that $u_{n}=T_{r_{n}} y_{n}$, we obtain

$$
f\left(u_{n}, y\right)+\frac{1}{r_{n}}\left\langle y-u_{n}, J u_{n}-J y_{n}\right\rangle \geq 0, \quad \forall y \in C .
$$

From (A2), we have

$$
\left\langle y-u_{n}, \frac{J u_{n}-J y_{n}}{r_{n}}\right\rangle \geq-f\left(u_{n}, \gamma\right) \geq f\left(y, u_{n}\right), \quad \forall y \in C .
$$

Letting $n \rightarrow \infty$, we have from $u_{n} \rightarrow x^{*}$, (2.8) and (A4) that $f\left(y, x^{*}\right) \leq 0(\forall y \in C)$. For $t$ with $0<t \leq 1$ and $y \in C$, let $y_{t}=t y+(1-t) x^{*}$. Since $y \in C$ and $x^{*} \in C$, we have $y_{t} \in$ $C$ and hence $f\left(y_{t}, x^{*}\right) \leq 0$. Now, from $(A 1)$ and $(A 4)$, we have

$$
0=f\left(y_{t}, y_{t}\right) \leq t f\left(y_{t}, y\right)+(1-t) f\left(y_{t}, x^{*}\right) \leq t f\left(y_{t}, y\right)
$$

and hence $f\left(y_{t}, y\right) \geq 0$. Letting $t \rightarrow 0$, from $(A 3)$, we have $f\left(x^{*}, y\right) \geq 0$. This implies that $x^{*} \in E P(f)$. Thus, $x^{*} \in F$.

Finally, since $x^{*}=\Pi_{\bar{C}} x_{1} \in F$ and $F$ is a nonempty closed convex subset of $\bar{C}=\cap_{n=1}^{\infty} C_{n}$, we conclude that $x^{*}=\prod_{F} x_{1}$. This completes the proof.

In Hilbert spaces, Theorem 2.1 reduces to the following theorem. 
Theorem 2.2 Let $C$ be a nonempty, closed and convex subset of a Hilbert space $H$ and let $T_{i}: C \rightarrow C$ be a closed and generalized quasi- $\varphi$-asymptotically nonexpansive mapping with real sequences $\left\{k_{n, i}\right\} \subset[1, \infty)$ and $\left\{c_{n, i}\right\} \subset[0, \infty)$ such that $\lim _{n \rightarrow \infty} k_{n, i}=1$ and $\lim _{n \rightarrow \infty} c_{n, i}=0$ for each $1 \leq i \leq N$. Let $f$ be a bifunction from $C \times C$ to $\mathbb{R}$ satisfying (A1)-(A4). Assume that $T_{i}$ is asymptotically regular on $C$ for each $1 \leq i \leq N$ and $F=\left(\bigcap_{i=1}^{N} F\left(T_{i}\right)\right) \bigcap E P(f) \neq 0$. Let $k_{n}=\max _{1 \leq i \leq N}\left\{k_{n, i}\right\}$ and $c_{n}=\max _{1 \leq i \leq N}\left\{c_{n, i}\right\}$. Define a sequence $\left\{x_{n}\right\}$ in $C$ in the following manner:

$$
\left\{\begin{array}{l}
x_{0} \in H \text { chosen arbitrarily, } \\
C_{1}=C, \\
x_{1}=P_{C_{1}} x_{0} \\
y_{n}=\alpha_{n, 0} x_{n}+\sum_{i=1}^{N} \alpha_{n, i} T_{i}^{n} x_{n} \\
u_{n} \in C \text { such that } f\left(u_{n}, y\right)+\frac{1}{r_{n}}\left\langle y-u_{n} u_{n}-y_{n}\right\rangle \geq 0, \quad \forall y \in C, \\
C_{n+1}=\left\{z \in C_{n}:\left\|z-u_{n}\right\|^{2} \leq k_{n}\left\|z-x_{n}\right\|^{2}+c_{n}\right\}, \\
x_{n+1}=P_{C_{n+1}} x_{1}
\end{array}\right.
$$

for every $n \geq 1$, where $\left\{r_{n}\right\}$ is a real sequence in $[a, \infty)$ for some $a>0$. Assume that the control sequences $\left\{\alpha_{n, 0}\right\},\left\{\alpha_{n, 1}\right\}, \ldots .,\left\{\alpha_{n, N}\right\}$ are real sequences in $(0,1)$ satisfy $\sum_{i=0}^{N} \alpha_{n, i}=1 \alpha$ nd $\lim \inf _{n \rightarrow \infty} \alpha_{n, 0} \alpha_{n, i}>0$ for each $i \in\{1,2, \ldots ., N\}$. Then the sequence $\left\{x_{n}\right\}$ converges strongly to $P_{F} x_{1}$.

Remark 2.3 Theorems 2.1 and 2.2 extend the main results of [16] from quasi- $\varphi$-nonexpansive mappings to more general generalized quasi- $\varphi$-asymptotically nonexpan-sive mappings.

\section{Acknowledgements}

The research was supported by the science research foundation program in Civil Aviation University of China (2011 kys02), it was also supported by Fundamental Research Funds for the Central Universities (Program No. ZXH2009D021 and No. ZXH2011D005).

\section{Authors' contributions}

ZJ carried out the algorithm design and drafted the manuscript. HS conceived of the study and helped to draft the manuscript. All authors read and approved the final manuscript.

\section{Competing interests}

The authors declare that they have no competing interests.

Received: 18 September 2011 Accepted: 1 March 2012 Published: 1 March 2012

\section{References}

1. Blum, E, Oettli, W: From optimization and variational inequalities to equilibrium problems. Math Student. 63, 123-145 (1994)

2. Moudafi, A: Second-order differential proximal methods for equilibrium problems. J Inequal Pure Appl Math 4 (2003). (art. 18)

3. Takahashi, W: Nonlinear Functional Analysis. Kindikagaku, Tokyo (in Japanese) (1988)

4. Goebel, K, Kirk, WA: A fixed point theorem for asymptotically nonexpansive mappings. Proc Am Math Soc. 35, 171-174 (1972). doi:10.1090/S0002-9939-1972-0298500-3

5. Schu, J: Iteration construction of fixed points of asymptotically nonexpansive mappings. J Math Anal Appl. 158, 407-413 (1991). doi:10.1016/0022-247X(91)90245-U

6. Zhou, H, Cho, YJ, Kang, SM: A new iterative algorithm for approximating common fixed points for asymptotically nonexpansive mappings. Fixed Point Theory Appl. 2007, 64874 (2007)

7. Alber, Yl: Metric and generalized projection operators in Banach spaces: Properties and applications. In: Kartosatos, AG (eds.) Theory and Applications of Nonlinear Operators of Accretive and Monotone Type. pp. 15-50. Marcel Dekker, New York (1996)

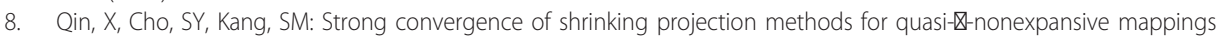
and equilibrium problems. J Comput Appl Math. 234, 750-760 (2010). doi:10.1016/j.cam.2010.01.015 
9. Zhou, H, Gao, G, Tan, B: Convergence theorems of a modified hybrid algorithm for a family of quasi- $₫$-asymptotically nonexpansive mappings. J Appl Math Comput. 32, 453-464 (2010). doi:10.1007/s12190-009-0263-4

10. Shahzad, $\mathrm{N}$, Zegeye, $\mathrm{H}$ : Strong convergence of implicit iteration process for a finite family of generalized asymptotically quasi-nonexpansive maps. Appl Math Comput. 189, 1058-1065 (2007). doi:10.1016/j.amc.2006.11.152

11. Liu, M, Chang, SS, Zuo, P: On a hybrid method for generalized mixed equilibrium problem and fixed point problem of a family of quasi- - -asymptotically nonexpansive mappings in Banach spaces. Fixed Point Theory Appl. (2010)

12. Tada, A, Takahashi, W: Weak and strong convergence theorems for a nonexpansive mapping and an equilibrium problem. J Optim Theory Appl. 133, 359-370 (2007). doi:10.1007/s10957-007-9187-z

13. Takahashi, S, Takahashi, W: Viscosity approximation methods for equilibrium problems and fixed point problems in Hilbert spaces. J Math Anal Appl. 331, 506-515 (2007). doi:10.1016/j.jmaa.2006.08.036

14. Zegeye, $\mathrm{H}$, Shahzad, $\mathrm{N}$ : A hybrid approximation method for equilibrium, variational inequality and fixed point problems. Nonlinear Anal Hybrid Sys. 4, 619-630 (2010). doi:10.1016/j.nahs.2010.03.005

15. Zegeye, $\mathrm{H}$, Shahzad, $\mathrm{N}$ : Convergence of Mann's type iteration method for generalized asymptotically nonexpansive mappings. Comput Math Appl. 62, 4007-4014 (2011). doi:10.1016/j.camwa.2011.09.018

16. Cho, YJ, Qin, X, Kang, SM: Strong convergence of the modified Halpern-type iterative algorithms in Banach spaces. An St Univ Ovidius Constanta. 17, 51-68 (2009)

17. Takahashi, W, Zembayashi, K: Strong and weak convergence theorems for equilibrium problems and relatively nonexpansive mappings in Banach spaces. Nonlinear Anal. 70, $45-57$ (2009). doi:10.1016/.j.na.2007.11.031

18. Mosco, U: Convergence of convex sets and of solutions of variational inequalities. Adv Math. 3, 510-585 (1969). doi:10.1016/0001-8708(69)90009-7

19. Beer, G: Topologies on Closed Convex Sets. Kluwet Academic Publishers Group, Dordrecht (1993)

20. Kamimura, S, Takahashi, W: Strong convergence of a proximal-type algorithm in a Banach space. SIAM J Optim. 13, 938-945 (2002). doi:10.1137/S105262340139611X

21. Ibaraki, T, Kimura, Y, Takahashi, W: Convergence theorems for generalized projections and maximal monotone operators in Banach space. Abstr Appl Anal. 2003, 621-629 (2003). doi:10.1155/S1085337503207065

22. Zegeye, $\mathrm{H}$ : A hybrid iteration scheme for equilibrium problems, variational inequality problems and common fixed point problems in Banach spaces. Nonlinear Anal. 72, 2136-2146 (2010). doi:10.1016/j.na.2009.10.014

doi:10.1186/1687-1812-2012-33

Cite this article as: Zhao and He: A hybrid iteration scheme for equilibrium problems and common fixed point problems of generalized quasi- $\varphi$-asymptotically nonexpansive mappings in Banach spaces. Fixed Point Theory and Applications 2012 2012:33.

\section{Submit your manuscript to a SpringerOpen ${ }^{\circ}$ journal and benefit from:}

Convenient online submission

Rigorous peer review

- Immediate publication on acceptance

- Open access: articles freely available online

- High visibility within the field

Retaining the copyright to your article

Submit your next manuscript at $\gg$ springeropen.com 